\title{
Conceptualising energy prosumption: exploring energy production, consumption and microgeneration in Scotland, UK
}

\author{
Authors names and affiliations: \\ Katherine Ellsworth-Krebs a (ke68@st-andrews.ac.uk) \\ Louise Reid a (lar9@st-andrews.ac.uk)
}

\begin{abstract}
a Department of Geography and Sustainable Development, University of St Andrews
Irvine Building, North Street, St Andrews, Fife, Scotland, KY16 9AL
\end{abstract}

Acknowledgements This work was funded by Economic and Social Research Council [grant number ES/K009516/1], Carnegie Trust [31680] and a PhD studentship at the University of St Andrews. The authors would like to acknowledge insights from Darren McCauley and Kirsten Jenkins on initiating investigation of energy prosumption; and thank the research participants who generously gave their time to this project and the helpful feedback provided by the anonymous reviewers and editor of this journal.

\begin{abstract}
Energy prosumption has become a common phrase as more householders and communities are producing and consuming their own electricity and heat. Prosumption is a combination of two words: production and consumption, and emerged as a concept at a time when consumers were beginning to be more proactive and take over steps traditionally thought of as 'production'. In many ways, energy prosumption is nothing new (e.g. wood combustion), yet development of our modern energy system has changed the relationships between energy producers and consumers (e.g. smart meters, renewable energy production). Thus, there is a growing body of research interested in the motivation and conditions for the uptake of microgeneration technologies and the implications to energy infrastructures and big energy producers. However, this 'energy prosumption' scholarship generally lacks a strong conceptual foundation and misses the opportunity to build on existing prosumption literature and related debates. This paper brings the wealth of literature on prosumption into the energy context and reflects on the insights offered by a prosumption lens. Our study explores a particular manifestation of prosumption - when a household is simultaneously a producer and consumer of their heat and/or electricity via microgeneration- and we present data from semi-structured interviews with 28 households living with microgeneration technologies in Scotland, UK. Thus, we provide a robust framework from which future research on household and community energy prosumption can build.
\end{abstract}

Keywords: prosumption; co-provision; renewable energy; microgeneration; UK 


\section{1: Introduction}

To save energy and money households may be encouraged to time their energydemanding activities, like washing and drying clothes, for sunny days. Using sunlight to dry clothes may seem like nothing new, but microgeneration technologies, such as photovoltaic panels, are transforming our modern energy system; changing not just when and where energy is used, but who produces it. Indeed, microgneration enables traditional energy consumers (e.g. households, communities, and organisations) to fulfil some of the same roles as traditional energy producers (e.g. power plants, the 'big six' in the UK). Thus, altering the fundamental geography of energy networks, blurring previously fixed distinctions between consumers and producers, sites of energy production and of use, and the relationship between supply and demand in general.

Microgeneration has become an important part of energy strategies for many governments because it has the potential to simultaneously lower carbon emissions, reduce the need for new generation and infrastructures by generating energy where it is used, and decrease energy costs to householders by adding to the diversity of the energy supply (Staffell et al., 2015). Therefore, microgeneration has the potential to play a substantial part in addressing major energy policy issues of climate change, energy security and affordability. In academic and grey literature, the term 'prosumption' has become popular to refer to these new relationships microgeneration technologies enable - or when a consumer is also a producer of their own energy. Yet, to date, these references to 'energy prosumption' currently overlook the extensive scholarship and conceptual foundation offered by prosumption and related concepts. Thus, this paper brings the wealth of literature on prosumption into the energy context and reflects upon how being involved in production may influence consumption, and vice versa.

To do so, this paper draws on data from in-depth interviews and ethnography undertaken in Scotland, UK, in 2014. In this paper, Scotland and the UK thus serve as an example of how energy prosumption is being implemented; however, these discussions are broadly of relevance to other nations. While communities and organisations are also transforming the energy system by becoming energy prosumers, our study explores prosumption at the household scale considering that this is a key sector in energy policy and research, accounting for a quarter of energy demand globally (Staffell et al., 2015). The paper begins by providing an overview of prosumption and explores the idea of energy prosumption. In section 3, we present our methodological framework and move on in section 4 to present our results. Section 5 frames our findings within the context of existing scholarship and then we draw our paper to a conclusion in section 6, airing some future priorities for research in relation to energy prosumption.

\section{2: Understanding prosumption}




\subsection{Prosumption Scholarship}

Prosumption is a combination of two words: production and consumption, which can be traced back to social theorist Alvin Toffler in his book The Third Wave (1980). Prosumption emerged as a concept at a time when consumers were beginning to be more proactive and take over steps traditionally thought of as 'production', for instance, collecting their own goods in a supermarket, do-it-yourself home improvements, and building self-assembly furniture. At the time, Toffler predicted a role for prosumption due to demand for 'de-massification' with self-customization eclipsing mass industrialisation of consumption, made possible by rapid advances in technology; in essence, a shift from volume to value. However, the conceptualisation of prosumption had largely been ignored by social science until recent years when its use for conceptualising the growth in user-generated online content or open-source computing (e.g. Web 2.0) (Beer and Burrows 2010, Denergi-Knott and Zwick 2012), has brought it back to the fore (Ritzer et al., 2010, 2012).

Prosumption has emerged at a time when scholars have increasingly been concerned with ideas of co-creation, co-production, co-provisioning (Chappells 2008, Chappells and Shove 2000), crowd sourcing and citizen science, concepts apparently similar since they all imply some greater sense of participation, and yet are different from prosumption (Dodge and Kitchin 2013). Like many of these related concepts, prosumption is considered a 'process rather than a single act' (Xie et al. 2008, p. 10). Prosumption can also allude to the emergence of prosumers (Kotler 2010), although those guided by social practice theories (Shove, 2003; Shove 2010) would give priority to the practice and critique focus on the practitioner or prosumer. Given this ontology, in the following paragraphs not only do we explore prosumption, but we also reflect upon the concept of co-provision, advocated by social practice theorists (Chappells et al. 2003, Van Vliet et al. 2005), and we explore the ways in which prosumption might build on such scholarship.

Scholars have long questioned whether production and consumption can or should be thought of as independent constructs since one is always and necessarily contingent on the other. Since the publication of Das Kapital (Marx 1867), the nature of the relationship between production and consumption has been hotly debated across many academic disciplines. Humphreys and Grayson (2008) highlight that consumers are themselves co-creators of value since before a product can be enjoyed, work is required (in their example a consumer still needs to charge, personalise and answer a mobile phone when it rings), ensuring that the consumer is complicit in the production of goods. Similarly, Ritzer (2014b) has argued that consumption is in fact a productive process because the consumer's identity and sense of self is constantly being produced and reproduced through consumption. Accordingly, consumption is never productionfree, and production and consumption are mutually inclusive, not exclusive. Unsurprisingly, advocates of prosumption argue that the theoretical separation of 
production from consumption is a false binary and that the "focus should always have been on the prosumer" (Ritzer and Jurgenson, 2010 p. 17, emphasis added).

Ritzer et al. (2012), and subsequently Ritzer (2014b), argue that the theoretical prioritisation of production over consumption (and vice versa) has shifted over time in relation to, for instance, processes of industrialisation (e.g. the increase and decrease in assembly line production). Accordingly, such prioritisation could be said to be temporally specific, indeed it is in recent decades, as a decline in traditional production (i.e. assembly line) has emerged, that the practice and theorisation of prosumption has become more prevalent. Yet, prosumption is not always possible and as Kotler (2010) reminds us, there are several forces attempting to inhibit prosumption. These include: that threatened interest groups may use the law to prevent people from producing certain goods and services themselves; that mass producers will seek to retain the structure of mass consumption by continuing to promote the hedonistic lifestyle; and, that few people will opt or be able to engage in $100 \%$ prosumption. Recent scholarship has, for instance, shed light on the more controversial elements of prosumption, including issues of exploitation (Comor 2010, Denegri-Knott and Zwick 2012) and protest (Earl 2013), suggesting that romanticised ideals of prosumption may be misplaced. The way in which power is experienced and implicated in relation to prosumption has therefore not been satisfactorily resolved. Nevertheless, the concept of prosumption offers great potential as a device to reveal the complexity of energy production and consumption relations.

\subsection{Energy prosumption}

In the case of energy, there has been evidence of an academic interest in prosumption and the energy prosumer (Burger and Weinmann 2014, Grijalva and Tariq 2011, Kesting and Bliek 2012, Pillai et al. 2014, Schleicher- Tappeser 2012). However, these studies lack an appreciation for the wider meanings and ideas underpinning the concept of prosumption. For example, whilst Schleicher-Tappeser (2012) and Kesting and Bliek (2012) write on energy prosumers, both stop short of fully conceptualising the meaning of prosumer (using only a footnote briefly acknowledging Toffler (1980)). Existing research on the energy prosumer can be characterised as having been limited largely to electricity prosumption from solar photovoltaic (PV) panels (Burger and Weinmann 2014, Kesting and Bliek 2012, Pillai et al. 2014, Schleicher- Tappeser 2012) and the development of smart grids. Instead we suggest that energy prosumption may be understood more broadly and not simply in electricity prosumption, but is equally applicable in the context of heat, and across all elements of the energy system (Chappells and Shove 2000, Van Vliet et al. 2012). For example, there exists literature on wood-burning stoves and other forms of domestic wood combustion (Devine-Wright et al., 2014; Peterson, 2008; Reeve et al., 2013), which is not conceptualised as prosumption, but is complimentary to these debates. 
Indeed, there is a considerable amount of energy research, which does not explicitly adopt the term 'prosumption' or 'prosumer' yet is relevant to developing the concept of energy prosumption. Most notably, microgeneration and distributed generation. The edited collection on Domestic Microgeneration (Staffell et al., 2015) is the first in-depth work that provides detailed reviews of ten microgeneration technologies and discusses them within a wider social, economic and political context. 'Microgeneration' refers to a diverse set of technologies which have marked differences in cost-effectiveness, suitability, output, and maturity (Staffell et al., 2015); understanding the particular characteristics and potentials of each technology should not be overlooked. The literature on microgeneration also highlights two areas that could be tightened up in conceptualising prosumption. Firstly, 'energy' and 'electricity' are often conflated, even though only a third of energy used in developed countries is supplied as electricity; whereas, heating is the main reason for domestic energy consumption in almost every country (Staffell et al., 2015). Thus, more explicit attention to what is being prosumed (e.g. heat, electricity or hot water) and how these demands relate to the wider energy system could be significant (e.g. justification for more research on heating technologies). Secondly, the term 'microgeneration' has loosely been adopted to refer to technologies that produce heat or electricity at the point where it will be used (Balcombe et al., 2014; Juntenen and Hyysalo, 2015); some of these technologies are highly efficient and use less fuel (e.g. heat pumps, combined heat and power) and others rely on a renewable energy source (e.g. solar thermal panels, PV panels, wind turbines, biomass boiler or stoves) (Staffell et al., 2015). Begging the question as to why certain energy practices are categorised as microgeneration. For instance, a heat pump is essentially an efficient electric heater so why are other efficiency improvements in heating systems not classified as microgeneration? Furthermore, given that a large proportion of the world's non-privileged population uses wood for cooking and heating (Staffell et al., 2015), the inclusion of biomass boilers critically overlooks how socioeconomic conditions allow certain energy practices to be categorised as microgeneration, and not others. Scholars interested in energy prosumption therefore have an opportunity to develop a more robust conceptualisation of the relationship between energy consumption and energy production as they converge in new ways.

Another complimentary area of literature comes from the concept of co-provision (Chappells and Shove 2000, Sauter and Watson 2007, Van Vliet et al. 2005, Watson 2004, Walker and Cass 2007) which has been developed to demonstrate how infrastructures shape consumption, suggesting that "different goods and services have specific characteristics which shape the ways in which they are consumed" (Chappells and Shove 2000, p. 8.41). This socio-technical perspective is a fundamental part of coprovision (as conceptualised by Van Vliet et al. 2005), yet is missing from prosumption scholarship and suggests a significant potential in developing the idea of prosumption further. The concept of co-provision thus offers a significant contribution to understanding the blurring boundary between energy producers and consumers. Certainly, it is our ambition to introduce many of the insights from the more 
theoretically robust conceptualisation of energy co-provision to inform energy prosumption research which, as we already suggested, has adopted the term with little consideration for its history.

Despite a greater conceptual development of co-provision in the context of energy up to this point, we argue that energy prosumption has been a more popular term to refer to exploring the implications of increasing microgeneration in both grey and academic literature; thus, ignoring prosumption (for co-provision) misses an opportunity to engage with, and inform, this research community. Furthermore, prosumption scholarship gives attention to issues of (in)justice and power, which social practitioners recognise to be limited in their own approach (Walker, 2013; Welch, 2015). For instance, prosumption scholars debate to what extent engaging in prosumption is empowering or exploiting for traditional consumers (Humphreys and Grayson 2008, Ritzer 2014). Moreover, some would suggest that prosumption is a way of producing and consuming goods or services that is different from dominant models of consumer culture predicated on mass production for mass consumption and thus has the potential to radically modify political, cultural and economic structures (Toffler 1980, Ritzer and Jurgenson 2010). While the potential for prosumption to be a revolutionary institution is debateable (Conor 2010), at the very least prosumption has the potential to alter the use (e.g. directly satisfies wants and needs, oriented towards object) and exchange values (e.g. the 'socially recognised universal equivalent of money,' oriented towards others) of a product (Humphrey and Grayson 2008). The aim of creating exchange value is so that the product can be sold to others; whereas, use value can be created through enjoying the outcome and/or taking part in the process of production (Ibid 2008). Energy prosumption then does not necessarily alter the exchange value, but has potential to create new patterns of demand through changing a product's use value (which could also be of interest in marketing microgeneration technologies). For example, a householder's sense of satisfaction from having a bath on a sunny day and knowing the hot water was produced on their roof is not captured simply in the monetary savings from not using their boiler on that day. Humphrey and Grayson (2008) suggest that there is critical potential in challenging existing social values through prosumption's ability to (re)create use values. This distinction between use and exchange values complements the critique of mainstream energy policy and research framing householders uptake of energy saving technologies being purely motivated by money saving or environmental concern (Aune, 2007; Walker et al., 2015).

What the preceding paragraphs have therefore attempted to do is indicate the boundaries of the concept of prosumption and its use in relation to community and domestic energy. It has highlighted areas of consensus and disagreement in the literature as well as identifying some important research gaps, specifically investigation of (1) whether/how living with a microgeneration technology may influence everyday life and hence energy consumption, (2) the process of choosing and installing microgeneration technologies, and (3) how experiences and motivations vary due to the 
diversity of microgeneration technologies. These are areas we have sought to explore in our own research, the details of which now follow.

\section{3: Methodology}

The research design was entirely qualitative, involving in-depth semi-structured household interviews in the homes of energy prosumers in two communities within Scotland; Fintry and northeast Fife. There are four reasons for focusing on rural areas. Firstly, these communities were identified because they are partly or wholly off the gas mains, which made them areas where increasing energy prosumption is both likely and appropriate. In rural areas not connected to gas mains, microgeneration can play a role in addressing issues of fuel poverty and affordability. Furthermore, domestic microgeneration may be more suited to rural areas (e.g. air flow not affected by other buildings for wind turbines, more likely to have garden space needed for installing ground source heat pumps) where other renewable production options are less easily shared (e.g. district heating, combined heat and power for a block of flats). Finally, switching from gas to a heat microgeneration technology is a substantial cost hurdle (Connor et al., 2014).

Moreover, in both Fintry and north-east Fife there were locals who had set up energy advice centres (e.g. Fintry Development Trust and St Andrews Energy Network) and these organisations helped us recruit householders who they knew had installed microgeneration technologies. Recruitment began with the help of these energy advisors and snowballed as households that participated often knew other households with microgeneration technologies. Whilst we recognised that there exists a broad continuum of energy prosumption activities (e.g. installing low-energy light bulbs is consumer activity that influences demand and thus production) (Ritzer, 2010; Van Vliet et al, 2000), our research sought to explore a particular manifestation of prosumption when a household is simultaneously a producer and consumer of their heat and/or electricity via microgeneration. Our results present analysis of householder's responses to "why did you get this system?" and "do you think the way you have used energy has changed?". Interviews also involved a house tour, enabling us to observe and speak about how microgeneration technologies are physically incorporated into the home and everyday practices. A deductive approach was taken towards analysis to extract emergent themes to understand energy prosumption. Specifically, we were interested in the experience of living with a microgeneration technology, the process to become a prosumer, and the way in which this varied in accordance with the technology installed.

In total there were 28 interviews with 58 householders and each interview was recorded and transcribed. In practice it proved easier to gain access to some microgeneration technologies than others, as reflected in the varying totals across Table 1 (households were counted multiple times if they had multiple technologies). This also highlights the different support for and maturity of each technology, which we reflect on in the next section. For reasons of confidentiality all interviewees have been given pseudonyms. 
Table 1. Number of households living with each technology

\begin{tabular}{|l|l|}
\hline Technology & Number of households \\
\hline Photovoltaic panels & 19 \\
\hline Wood-burning stoves/ranges & 13 \\
\hline Solar thermal panels & 9 \\
\hline Heat pumps (air and ground) & 8 \\
\hline Wind turbines & 4 \\
\hline Biomass boilers (pellet and logs) & 3 \\
\hline
\end{tabular}

\section{4: Results}

Stressing the limitations of generalising about prosumption and treating all types of microgeneration as homogeneous, we organise our results around what is being prosumed, heat (4.1) or electricity (4.2), and consider each technology in turn. It is important to draw a distinction between electricity and heat prosumption. Electricity is more versatile, partly because it can be sold back to the grid, and has been the focus of government's incentives schemes (Connor et al., 2015). However, heating is the single biggest use of energy in the UK and cannot be overlooked in strategies to meet legally binding renewable and carbon emission targets (Chaudry et al., 2015). The microgeneration technologies are ordered according to the number of households in our sample with each technology (Table 1), making it clear to the reader the amount of empirical data we base our results on and enabling us to compare the popularity of some technologies in our sample to national figures. We aim to contribute to a more nuanced conceptualisation of energy prosumption and this also enables us to maintain a holistic perspective, considering the general differences between prosumption of heat and electricity, as well as exploring the more particular issues or strengths related to a specific microgeneration technology.

\subsection{Heat prosumption}

Admittedly heat prosumption makes up a tiny percentage of overall energy consumed in UK homes, in 2013 only about 2.8 percent of heat was generated from renewables (DECC, 2014b). Furthermore, the focus on generating electricity means that only around 15 percent of all renewables were used to generate heat in 2013 (Ibid, 2014b). Of this, domestic use of wood is the main contributor (roughly 35 percent) and heat pumps contributed another 5 percent (the rest being mainly from non-domestic use of biomass and wood); our sample reflects this with wood-burning stoves being the most common microgeneration technology. 
The UK's domestic Renewable Heat Incentive (hereafter RHI) is novel in a global context because it is the first scheme to subsidise heat microgeneration, operating like a FiTs and replacing grant schemes - the common funding mechanism for renewable heat (Connor et al., 2015). While originally introduced into UK legislation in the 2008 Energy Act, the RHI did not start until April 2014, resulting in confusion and uncertainty for both industry and householders (Ibid, 2015). This delay was attributed to the complexity of designing support for large-scale uptake of renewable heating microgeneration, (unexpected) changes to the renewable energy policy made by the Coalition Government elected in 2010 (Connor et al., 2015), and the cheap gas supply in the UK (Chaudry et al., 2015). This confusion is reflected in the UK Government's data on the uptake of the RHI, which suggests that a large number of applications in the first year were refused due to householder's misunderstandings regarding the application process and metering requirements (DECC, 2014b). Moreover, in 2014 the vast majority (86\%) of accredited installations were in place before the scheme launched and retrospectively applied for (Ibid, 2014b), indicating that this new system of funding may not be the main motivation for householder's choosing to install microgeneration for heating. Our study is timely because it offers some insights into other considerations influencing householder's uptake. At the point of writing, there have been no other empirical studies investigating householder's experience with the RHI in the UK, although other research has emphasised financial factors, trustworthy information, and fears of influencing home resale values as important concerns for investing in microgeneration technologies (Balcombe et al., 2014).

All of our households had installed their microgeneration heating systems before April 2014 and thus were planning to apply retrospectively for the RHI, had received a oneoff grant under the interim funding scheme, or (a few) did not even know that there was funding that they were eligible for. Even though interviews occurred in summer 2014, none of our households had completed their applications and there was a common complaint that the whole process was unclear, cumbersome and "intensely tedious" $(\mathrm{m} 1$, $\mathrm{hE}$ ). After installing a solar thermal panel, one householder said that the company promised to "'get in touch when it is up and running' and at that stage it [the RHI] was imminent, and that was four years ago" (m1, h10). Furthermore, some householders were keenly aware of the continued delay of the RHI, one commented that he felt "conned into going for it" (m1, h21) because they had been waiting so long for the RHI to actually start. All our households could speak extensively about the huge amount of research that went into choosing a heating technology (e.g. suitability, finding a reliable installer, affordability and understanding funding options, Energy Performance Certificates) and at least one person in the household had to be quite proactive in order to make this shift from a conventional heating option. Certainly, the role of energy advisors, characterised by participants, as independent and reliable support was a catalyst for investing in heating microgeneration. This is a point we return to again in section 4.2 because more households mentioned their experiences with scams, cowboy builders, and installers going out of business in relation to electricity generating 
technologies. Whereas, heating microgeneration technologies are much newer and less common so any advice was valued because householders often explained that they were "making all of these decisions on the hoof as best [they] could on systems that were untried and untested or in very early stages of being used" (m1, h21).

The monetary cost, both installation and operating costs, was undoubtedly an important factor in householder's decision to invest in heating microgeneration, and several of our households mentioned that their energy bills had roughly halved since switching to biomass boilers or heat pumps $(h I, h H, h F)$. This is not an insignificant saving considering that the conventional heating options for these households (e.g. electric storage heaters, oil or gas canisters) are relatively expensive compared to households on the gas mains and several participants quoted annual energy bills, before switching, as being over $£ 4,000$ (average dual fuel bill is roughly $£ 1,344$ nationally; DECC, 2015c). Thus, several households suggested that even without the RHI or one-off grants they probably would have put these technologies in because it made heating their homes affordable. Unsurprisingly, this was not a claim made by all households. For example, two participants that had wanted heat pumps, and had not installed them, said it was because heat pumps were too expensive. Moreover, the heat pump itself may have been affordable, but the other energy efficiency improvements were not. Snape et al. (2015: 34) identifies this as the "hassle factor", having to make energy efficiency improvements or changing radiators before qualifying for the RHI and suggests that this is largely why uptake for the RHI has been lower than expected.

However, whilst householder's justification of their decisions often related back to financial considerations, Gram-Hannsen (2014) demonstrates that this is generally a retrospective justification and decisions to retrofit homes are much more complicated. This is part of why understanding the way each technology 'fits' into existing homes and lifestyle expectations is so necessary. For instance, heat pumps may be desirable to some householders because they are similar to conventional heating systems compared to biomass boilers which require regular loading of pellets- this may be useful for marketing or explaining the success (or not) of some technologies. Subsequently, the rest of the section focuses in on the experiences of living with each heating microgeneration technology.

\subsubsection{Wood-burning stoves and range units}

In our research, we found that wood-burning or multi-fuel stoves and range units require work in order to produce heat: starting a fire is undoubtedly more work than flipping a switch to turn on central heating. In some cases, this form of prosumption required householders to devote significant effort to heat their home. Chain-sawing, chopping, stacking, and drying wood, as well as dealing with the disposal of ash, were common in many of the wood-burning households we interviewed. Some of these 
practices were undertaken routinely, if not daily. For the majority of participants being part of the production process was described with a sense of satisfaction:

I like practically, physically making [the fire] happen, that is really satisfying" f1, h18

Therefore, engaging in the process of wood-burning is an example of how being involved in production adds value to the act of consumption (e.g. use value), which is not simply related to financial considerations or savings (e.g. exchange value). Another part of this work included regulating heat output or 'topping up' the stove or range unit:

"I can finely control [the Rayburn]. If I want it very hot, I can open things up and it will boost the heat, it will take maybe half an hour, 40 minutes, because that is how long it takes" m1, h11

This is important because taking part in producing heat could in turn influence householders' expectations around how their home was heated (e.g. not expecting instantaneous shifts in indoor temperature, wearing their coat when first getting home). Similarly, many of our other participants often used their stove or range unit as a 'roomheater', instead of heating the whole house through the central heating system, they confined the demand for heat to a smaller part of the house. For example, this was a major benefit Emma attributed to having a wood-burning stove in their living room:

"If we didn't have [the wood-burning stove] and we didn't, you know in the winter, come and sit in this room at night, then our cost for this house would be massive, wouldn't it, to leave the heating on" $f 1, h 4$

Hence wood-burning prosumption simultaneously changes or shapes the nature of both production of heat and the wider routines of householders. The idea of householders not needing to heat all the rooms in the home or accepting the variability in indoor temperatures, suggests a form of prosumption that involves not only a high degree of effort, but also shows how energy production and consumption are interdependent. Wood-burning therefore is a prime example of the utility of adopting a prosumption lens because the extra involvement in production required by householders added value to their heating practices and furthermore has the potential to make householders reflexive of their heat consuming practices.

\subsubsection{Solar thermal panels}

Living with solar thermal panels (for hot water) has potential for householders to be active or engaged consumers and take advantage of using their own energy production. However, while several households suggested that " a hot bath that has been solar heated is even more pleasurable than a normal hot bath" (m1, h10) there was less discussion about shifting bathing or hot water-consuming practices in relation to when solar 
thermal panels were producing. For the most part, production was not capitalised upon because it did not fit with particular expectations or daily rhythms (i.e. timing of bathing and showering practices). Mainly, solar thermal households spoke about the seasonal fluctuation of this technology and getting nearly all of their hot water in the summer from their own energy production. Again, this is an example of production not fitting with demand and Mary explained that this actually led to "decadent" use of their excess hot water:

"In the hot, hot sunny days we have excess hot water because it is boiling all day [...] because it's free, you don't even want a bath on days like that, so [the kids] have a hot paddling pool out in the garden or the sprinkler spraying hot water" f1, h18

Whilst solar thermal panels clearly added to householder's enjoyment of consuming hot water (e.g. use value), for the most part this form of prosumption did not lead householders to reduce or shift their hot water consuming practice. Solar thermal panels lead to a 'use it or lose it' mentality and Mary's anecdote highlights the potential for solar thermal panels to actually increase consumption.

\subsubsection{Ground and air source heat pumps}

Heat pumps function sufficiently like 'normal' central heating systems, making them desirable to many households because they require no routine or daily interaction to produce heat and costed less to run than conventional heating. Householders did not feel that they needed to be conscious of their energy demand because savings were achieved by the technology itself. Kate articulated this when she explained that their ground source heat pump uses the same amount of electricity to heat their whole house as an electric fire normally demands.

"That [heat] pump uses 1.8Kws per hour and it heats our entire house and gives us all the hot water that we want and that is just a two bar electric fire" f1, h19

Heat pumps are generally controlled through a thermostat to mimic conventional central heating, meaning that after the initial effort of installation householders are not actively involved in production. Many participants stressed that they "loved" living with this technology and commented on enjoying a warmer house, with a more consistent temperature "all the time" (h19, h21). The heat pump then altered households' experience of comfort in the home but did not make householders reflective of their heating practices or add value through involvement in producing their own heat.

\subsubsection{Biomass boilers}

Biomass boilers require regular loading of pellets, even for automated feed systems, requiring relatively more engagement in production. The level of effort required in 
production will vary between different models and types of biomass boiler, with some, but not all, requiring daily loading and weekly cleaning in the winter. Furthermore, involvement in production may not be the same for all household members. Harry did not seem to mind loading pellets a few times a week and his wife Sarah also knew how to work the biomass boiler, but she in particular wished they could have a bulk feeding system so "that would save [her] having to constantly empty bags of pellets" (f1, h5). While biomass is a form of burning wood there was less emphasis on the satisfaction of being involved in production, as loading pellets requires less effort than wood harvesting or managing a fire. Nevertheless, Rhona did mention that loading pellets add value because it made her feel more connected to the energy her family was consuming:

"It is quite a physical thing to do and I quite like that because it is about connecting with the energy that you are using, because you physically pick up the energy and you pour it in" $f 1, h 14$

However, for the most part, biomass boilers were similar to heat pumps in the sense that they both fit into expectations of "normal" central heating systems and did not generally lead householders to reflect on their heat consuming practices.

\subsection{Electricity prosumption}

In comparison to heating prosumption, the contribution of renewables to electricity generation is considerable, accounting for 17.8 percent of electricity consumed in the UK in 2014 (DECC, 2014b). Only about 4 percent of renewable electricity comes from PV panels, which is mainly at a domestic scale (98\%), and over half is from wind (majority being large-scale with very little domestic generation) (DECC, 2014b).

Unlike the novelty of the UK's funding scheme for heating prosumption (i.e. the RHI), FiTs are widely recognised to have driven growth in electricity microgeneration globally, especially the widespread success of PV panels which are nearing costcompetitiveness and grid-parity (i.e. in some countries PV can be installed without subsidies and the electricity generated is (soon to be) less than or equal to the price of purchasing from the electricity grid) (Brandon, 2015; Jardine, 2015; Smith et al., 2014). For instance in the UK, the FiTs for electricity microgeneration started in April 2010 and in the first 5 years there has been over 680,000 PV installations, this is significantly ahead of original projections for 750,000 installations by 2020 (DECC, 2015b). Furthermore, the overall costs of PV in the UK have come down dramatically since the FiTs was introduced, before a $4 \mathrm{kWp}$ installation cost $£ 12,500$ and in July 2015 a typical $4 \mathrm{kWp}$ system would cost $£ 5,600$ (Anderson, 2015; Jardine, 2015). Due to this high uptake and a dramatic reduction in the costs of PV installations, the FiTs was reduced (due to an unscheduled review instigated by the new Coalition Government (Smith et al., 2014)) and many of our participants commented on their delight (or not) in getting in on the initial rate: 
"I got one of the early ones; I get the 43 something pence [Feed-In Tariff]. But of course, I suppose you could say I had to trade that for panels these days which might be cheaper to install and maybe more efficient" $f 1, h 17$

Nonetheless, nearly all of our households explained their decision to install PV was because it was a safe investment with little hassle and "the only research is to get the price and to see what you can afford" (f1, h17). Certainly, our sample reflects the relative popularity of PV as two-thirds of our households had this microgeneration technology.

Whereas, domestic (pole-mounted) wind turbines are less common, more expensive than PV and their installation cost has not been dramatically driven down since introduction of the FiTs; in 2014 a typical 2.5 or $6 \mathrm{~kW}$ system costs between $£ 10,000$ and $£ 30,000$ (EST, 2014c). While wind turbines are meant to payback in roughly 14 years (Infield and Staffell, 2015), the experience of our householders suggested that there was more risk and uncertainty in installing wind turbines as maintenance costs are considerable, making warranties and installers staying in business more of a concern. While PV has no moving parts and essentially no maintenance costs (Jardine, 2015), there is relatively less known about the long-term durability and performance of domestic wind turbines (Infield and Staffell, 2015) and three of our four households with wind turbines complained about high annual maintenance costs (e.g. £200-300) and replacement parts cutting into their payback time scale (h10, h19, hG). Thus, for the most part our participants that invested in wind turbines were less motivated by financial considerations; Ron explains that "it was partly a business decision but it was very much driven by an ethical and philosophical commitment [...] There is so much wind blowing past the site that not to harness a percentage of it just feels like a waste. It feels inefficient not to have it" ( $\mathrm{m} 1, \mathrm{~h} 10)$. However, all of our wind turbine households had also installed PV panels and spoke more favourably about that investment (e.g. rate of return, no maintenance issues).

In comparison to installing heating microgeneration technologies, energy advisors support on PV was less important. PV panels are relatively mature and established with many experienced installers (Jardine, 2015) and our participants suggested it was more a matter of "shopping around" for a reliable installer than debating the suitability of the microgeneration technology. However, there was some mention of 'cowboy' installers (e.g. overpriced and sub-standard quality) and even scams, so householders often stressed the need to be savvy when investigating their options:

"It has been a bit Wild West, the whole renewables thing. It is like any new sector that opens up, you get the cowboys" m1, h10

Therefore, while choosing a heating microgeneration technology involved many more considerations (e.g. suitability to building fabric and radiators, level of 'effort' involved 
in production, cost, disruption during installation), choosing PV was a relatively simple and safe investment, being a relatively mature technology due to the FiTs and is also less disruptive (e.g. external installation on roof that generally requires no extra refurbishment). Nonetheless, the visibility of energy (through meters) and its effect on consumption is something that has been a focus of domestic energy research (Darby 2010, Hargreaves et al. 2010, 2013) and part of householder's generating their own electricity is the potential for this to influence their electricity demand. Subsequently, the rest of section 4.2 reflects on how living with each electricity microgeneration technology may reduce demand.

\subsubsection{Photovoltaic panels}

Many households with PV panels described having a routine for running their appliances, including waiting to hoover and run the washing machine or dishwasher on a sunny day to maximise use of the energy they generated. Jonathon explained seeing how much electricity they produced led him and his wife to shift their use of electricity:

"You just get a better feel for what your energy consumption is. In our view, it then becomes almost like a game" $m 1, h 9$

By describing the process of consuming electricity as "a game" this suggests that having PV panels can add enjoyment (e.g. use value), that is not simply dependent on financial savings (e.g. exchange value). However, previous studies on householders with PV panels found that in some cases, having PV panels led to an increase in electricity consumption because it was 'free' (Abi-Ghanem and Haggett, 2011; Baborska-Narozny et al., 2016; Strengers, 2013). Similarly, whilst our participants generally made some effort to shift their electricity consuming practices to when their PV panels were producing, they were not necessarily trying to reduce overall consumption. This raises issues over the perceived 'goal' of microgeneration or prosumption, which we reflect on in section 5, whether it is to reduce carbon emissions or overall energy consumption, or even to address issues of affordability or energy security. Thus, PV panels have the potential to add value to householder's experiences of consuming electricity and to shift electricity-demanding practices. However, this potential will not necessarily be realised as householders can still benefit financially from installing PV panels without making efforts to be actively involved in production or altering their consumption.

\subsubsection{Wind turbines}

Our wind turbine households commented upon the difficulty of matching their electricity demand to their production. Ron explained that he had hoped his family would alter their lifestyles to maximise on the "free power" from their two wind turbines but that this did not happen in reality. For example, while Ron mentions encouraging his wife to use the tumble dryer when it is windy he emphasised that these sorts of changes did not fit with other aspects of daily life: 
"She gets it completely, but life is busy. And in practice it is very rare that she takes a decision to time her laundry for windy days. There are particular moments in the week when it has to be done, that is her schedule that is when it is done. If it is windy, great, if it's not, tough; that is the honest answer" m1, h10

Clearly the issue here is not one of awareness, education or motivation, but the rhythm of everyday life and the way in which this is organised (e.g. being out at work during the day). Another wind turbine participant made a similar example suggesting that it would be ridiculous to not watch television because there is no wind, "there is more to life than that" ( $m 1, h 19)$. In some cases then, being closer to production is not sufficient to encourage a shift in consumption. Furthermore, considering that all of our participants complained about the high maintenance costs for their wind turbines and unexpected issues (e.g. blades and bolts being damaged), living with this microgeneration technology did not necessarily add to their sense of satisfaction when consuming electricity. Certainly, wind turbines are not praised for their suitability to a domestic scale (Staffell et al., 2015), nor were our participant's experience encouraging.

\section{5: Discussion}

Our review of literature on prosumption, microgeneration and co-provision indicated three areas deserving greater consideration in research of the blurring boundaries between energy producers and consumers.

Firstly was the need to attend to the conflation between energy and electricity, which has trivialised the significant energy demand from heating. We argue that heating technologies, which have not come under the term 'energy prosumption' in academic literature to date, not be overlooked in subsequent scholarship. For instance, our study presented results on the experience of householders with both electricity and heat microgeneration technologies. Importantly, our study is the first of its kind to report on householder's perception of the newly introduced RHI (April 2015). Similarly to studies on support mechanisms for electricity microgeneration (Smith et al., 2014), we found that a sense of risk and uncertainty around government funding may have a greater influence than the funding mechanism itself (e.g. grants, loans, pay for heat production)(Chaudry et al., 2015; Connor et al., 2015); considering that the majority of our households were applying retrospectively and complaints about the delay and misinformation about when the RHI would begin was common. In comparison to choosing to invest in electricity microgeneration, householders stressed the lack of maturity of heating technologies and subsequently local energy advice and impartial support was integral to inform their decision to choose an appropriate technology (e.g. advice is also needed because changing the heating system is generally more disruptive and complex than the installation of PV panels and wind turbines which are largely external). It was clear that the challenge of increasing energy prosumption is arguably 
at least as much institutional as technical; creating a sense of stability and support around (heating) microgeneration technologies (i.e. avoiding U-turn policy changes following a majority political party change) is essential to increasing energy prosumption. Nevertheless, it remains that energy prosumption should be a term which encompasses both heat and electricity prosumption.

Secondly, we have sought to acknowledge the diversity of microgeneration technologies and therefore to not generalise the process or experience of energy prosumption. Thus, our study presented results individually on six microgeneration technologies. We were interested in the extent to which being involved in energy production influenced prosumers' energy consumption and we found that this varied considerably by the microgeneration technology. Wood-burning stoves and PV panels appeared to offer the greatest potential to use value, giving householders an added sense of satisfaction by being involved in production or shifting their heat and electricity-demanding practices. Whilst the emptying of pellets into biomass boilers may have a similar effect, for the most part biomass, solar thermal panels, and heat pumps did not lead householders to re-evaluate their consumption; either the technology functioned sufficiently like normal (e.g. thermostatically controlled central heating) or it was too much effort to capitalise on the timing of production (e.g. too much hot water in the summer or no hot water in the morning). Moreover, not only did wind turbine households make little to no effort to shift their electricity-consuming practices when windy (e.g. using the tumble dryer or hoover), these participants were sceptical of the suitability of this technology to domestic scale production. This serves to highlight the importance of not generalising the suitability of prosumption because the 'best' technology will depend on the context and scale. For instance, our study suggested that wind turbines are inappropriate at a domestic scale (e.g. cost of installation and maintenance); nonetheless, wind turbines produce the majority of electricity from renewables in the UK (DECC, 2014b) and suit production at a larger scale or by other prosumers (e.g. farmers or community groups). Indeed, householders are not the only energy prosumers and this is an exciting time for small businesses and communities as the decreasing costs and increasing distribution of microgeneration technologies enable consumers to alter their involvement in energy systems.

Finally, we aimed to explore the implications of the main argument that prosumption scholarship offers to energy researchers, which is that production and consumption are inextricably linked (Ritzer, 2014a, 2014b). The majority of microgeneration research is symptomatic of energy research in general, being dominated by building and engineering scientists and a techno-economic framing of change (Strengers, 2013). Prosumption was originally portrayed in revolutionary terms (Toffler, 1980), reflecting on the politics of mass production for mass consumption; thus in the context of energy, the term 'prosumption' may be used to signal a more radical vision of the goal of increasing microgeneration as a way to shift power back into the hands of everyday people and challenge the hedonistic lifestyle (Kotler, 2010). This agenda in prosumption scholarship compliments a common critique made by domestic energy researchers 
(Ellsworth-Krebs et al., 2015; Reid and Houston, 2013) arguing that technical interventions, like microgeneration technologies, fail to engage with social considerations and the way in which consumption is created. However, even within prosumption scholarship there is debate over the extent to which consumers taking over (more of) production, and thereby becoming more conscious of their consumption, actually challenges consumer culture (e.g. encouraging creativity and self-sufficiency that liberates humanity to see beyond commodity-framed relationships; Toffler, 1980) or simply becomes another means of marketing with the effect of increasing consumption rather than reducing it (e.g. 'doing your bit')(Comor, 2011). Understanding the potential that an increase in microgeneration has on reducing energy consumption is much more complex than improving the efficiency and uptake of these technologies. As our and multiple other studies on microgeneration have also found (Abi-Ghanem and Haggett, 2011; Baborska-Narozny et al., 2016; Strengers, 2013), being an energy prosumer can lead householders to use more electricity or heat because of the perception that this energy is 'free'. Increasing microgeneration alters our energy system in subtle and unexpected ways and understanding these intricacies is what deserves further attention in energy discourses. How does microgeneration contribute to matching production to peak demand? When/where is it better to use energy at the point of production or store it (e.g. there is an add-on to PV panels to divert electricity to heating hot water when sunny, but what if this hot water is not used)? Who benefits from sending electricity 'back' to the grid? What is the relative importance of shifting energy demand as opposed to reducing demand? Certainly, this is why BaborskaNarozny et al. (2016) warn that microgeneration technologies need to be marketed not just for financial juggling of energy but genuine energy saving practices because the impact of these changing producer-consumer relationships is diverse. Hence, the concept of prosumption supports calls for more socio-technical investigation of energy demand (Hargreaves et al., 2010).

\section{6: Conclusion}

This paper sought to offer a clearer foundation for the fledgling scholarship on the energy prosumer (Burger and Weinmann, 2014; Kesting and Bliek, 2012; Pillai et al., 2014; Schleicher-Tappeser, 2012). We argued that energy should not be conflated with electricity, especially considering that heating makes up the majority of domestic energy demand in any country (Staffell et al., 2015). Our study therefore included prosumers of both electricity and heat. Certainly, the funding mechanisms, support available, and our participants' experiences differed depending on whether electricity or heat was being prosumed and as a result of the particular characteristics of each microgeneration technology. In general, advice and support for heating prosumption was more important to householders' decision to become a prosumer. In part, this is because heating technologies are less established and their installation in the home is 
generally more complex and disruptive. The implications of becoming an energy prosumer were diverse, and at times, but not always, led to new patterns of consumption. Blurring the traditional boundary between energy supply and demand reshapes the way in which energy networks are structured and regulated.

Further, we begun to question, and encourage others to consider, whether energy prosumption is a 'techno-fix' or actually challenges consumer society (Abi-Ghanem and Haggett, 2011; Toffler, 1980), and what the implications are for everyday life and expectations of home that may co-evolve with the introduction of microgeneration technologies (Shove, 2003; Van Vliet et al., 2000). Ultimately, we have argued and demonstrated that there is significant value in adopting a prosumption lens to energy research. We have suggested that using the term prosumption should signal an appreciation of a socio-technical understanding of the energy system - that changes in technologies and physical infrastructures influence, and are influenced by, social conventions that shape energy-demanding activities.

By exploring the concept of prosumption in relation to microgeneration we have identified several areas in which future scholarship may offer a more critical and holistic investigation of the implications of blurring boundaries between energy production and consumption. Specifically, we argue for future reflection on power relations that impact the uptake and access to microgeneration technologies (e.g. interests and lobbying power of mass producers)(Kotler, 2010). For instance, are lowincome households subsidising installation of PV panels? Are householders taking on government or energy companies' responsibilities? Such questions suggest that greater reflection of the context and implications of the socio-economic conditions of energy prosumers (e.g. a large proportion of the world's non-privileged population are prosumers as they use wood for cooking and heating) is required. Prosumption therefore presents energy companies, regulators, consumers, and developers with a new set of challenges, but equally with new opportunities. The concept of energy prosumption thus offers a novel framework for future microgeneration research.

\section{Bibliography}

Abi-Ghanem DA, Haggett C, 2011 “Shaping people's engagement with microgeneration technology" In: P Devine-Wright, Ed Renewable Energy and the Public (London, Earthscan)

Anderson K, 2015 "Solar panel costs, benefits and savings" Solar Guide available at: http://www.solarguide.co.uk/solar-panel-costs-benefits-and-savings

Aune M, 2007 “Energy comes home” Energy Policy 35 (11) 5457-5465 
Baborska-Narozny M, Stevenson F, Ziyad F, 2016 "User learning and emerging practices in relation to innovative technologies: a case study of domestic photovoltaic systems in the UK" Energy Research and Social Science in press

Balcombe P, Rigby D, Azapagic A, 2014 "Investigating the importance of motivations and barriers related to microgeneration uptake in the UK" Applied Energy 130 403-418

Beer D, Burrows R, 2010 “Consumption, prosumption and participatory Web cultures: an introduction" Journal of Consumer Culture 10(1) 3-12

Burger C, Weinmann J, 2014 "Chapter 3 - Germany's Decentralized Energy Revolution”, in Distributed Generation and its Implications for the Utility Industry Ed F P Sioshansi (Academic Press, Boston) 49-73

Chappells H, 2008 "Systematically sustainable provision? The premises and promises of 'joined-up' energy demand management" International Journal of Environmental Technology and Management 9(2) 259-275

Chappells H, Shove E, 2000 “Organising Energy: Consumption, Production, and CoProvision" accessed from http://aceee.org/files/proceedings/2000/data/papers/SS00_Panel8_Paper04.pdf

Chaudry M, Abeysekera M, Hosseini SHR, Jenkins N, Wu J, 2015 “Uncertainties in decarbonising heat in the UK" Energy Policy 87 623-640

Comor E, 2011 "Contextualising and critiquing the fantastic prosumer: power, alienation and hegemony" Critical Sociology 37 309-327

Connor PM, Xie L, Lowes R, Britton J, Richardson T, 2015 “The development of renewable heating policy in the United Kingdom" Renewable Energy 75 733-744

Darby S, 2010 "Smart metering: what potential for householder engagement? Building Research and Information 52 126-134

Denegri-Knott S, Zwick D, 2012 “Tracking Prosumption work on eBay: Reproduction of Desire and the Challenge of Slow Re-McDonalidization" American Behavioural Scientist 56 439-458

DECC, 2014a "Community Energy in the UK: Part 2" Databuild Research and Solutions Ltd URN:13D/320

DECC, 2014b “Energy trends, June 2014” National Statistics Publication ISSN 2040-6029 
DECC, 2015a "Consultation on a review of the Feed-in Tariffs scheme" URN 15D/435

DECC, 2015b "Renewable sources of energy: Chapter 6, Digest of United Kingdom Energy Statistics (DUKES)" 1-39

DECC, 2015c “Quarterly Energy Prices, September 2015” National Statistics Publication URN 15D/276C

Devine-Wright P, Wrapson W, Henshaw V, Guy S, 2014 "Low carbon heating and older adults: comfort, cosiness and glow" Building Research \& Information 42(3) 288-299

Earl J, 2013 “Spreading the word or shaping the conversation: 'prosumption' in protest websites" Research in Social Movements, Conflicts and Change 36 3-38

Ellsworth-Krebs K, Reid L, Hunter CJ, 2015 "Home-ing in on domestic energy research: "House," "home," and the importance of ontology" Energy Research \& Social Science 6 100-108

EST, 2014a "Feed-In Tariffs Scheme (FITs)" accessed from: http://www.energysavingtrust.org.uk/Generating-energy/Getting-moneyback/Feed-In-Tariffs-scheme-FITs

EST, 2014b “Green Homes Network” accessed from: http://www.energysavingtrust.org.uk/scotland/Generating-energy/Green-HomesNetwork

EST, 2014c "Wind turbines" accessed from: http://www.energysavingtrust.org.uk/domestic/wind-turbines

Hargreaves T, Nye M, Burgess J, 2010 “Making energy visible: A qualitative field study of how householders interact with feedback from smart energy monitors" Energy Policy 38(10) 6111-6119

Hargreaves T, Hielscher S, Sefyang G, Smith A, 2013 “Grassroots innovations in community energy: The role of intermediaries in niche development" Global Environmental Change 23(5) 868-880

Gram-Hanssen K, 2014 "Retrofitting owner-occupied housing: remember the people” Building Research \& Information 42(4) 393-397

Humphreys A, Grayson K, 2008 "The intersecting roles of consumer and producer: a critical perspective on co-production, co-creation and prosumption" Sociology Compass 2 963-980 
Jardine C, 2015 "Chapter 7: Solar photovoltaic panels”, in Domestic Microgeneration: Renewable and Distributed energy technologies, policies and economics Ed Staffell I, Brett D, Brandon N, Hawkes A (Routledge, New York) 183-182

Juntunen JK, Hyysalo S, 2015 "Renewable micro-generation of heat and electricityReview on common and missing socio-technical configurations" Renewable and Sustainable Energy Reviews 49 857-870

Kesting S, Bliek F, 2013 “Chapter 14: From Consumer to Prosumer: Netherland's PowerMatching City Shows The Way", in Energy Efficiency Ed F P Sioshansi (Academic Press, Boston) 355-373

Kotler P, 2010 "The Prosumer Movement: A New Challenge for Marketers" in Mink B, and Hellmann K, Prosumer (Berlin, VS Verlag) 51-62

Marx K, 1867 Das Kapital, Kritik der politischen Ökonomie (Verlag von Otto Meisner)

Peters M, Fudge S, Jackson T, 2012 Low Carbon Communities: Imaginative Approaches to Combating Climate Change Locally (Cheltenham, Edward Elgar)

Petersen LK, 2008 "Autonomy and proximity in household heating practices: the case of wood-burning stoves" Journal of Environmental Policy \& Planning 10(4) 423-438

Pillai GG, Putrus GA, Georgitsioti T, Pearsall NM, 2014 "Near-term economic benefits from grid-connected residential PV (photovoltaic) systems" Energy 68 832-843

Reeve I, Scott J, Hine DW, Bhullar N, 2013 “This is not a burning issue for me: How citizens justify their use of wood heaters in a city with a severe air pollution problem" Energy Policy 57 204-211

Reid LA, Houston D, 2013 “Low Carbon Housing: A 'Green’Wolf in Sheep's Clothing?" Housing Studies 28(1) 1-9

REN21, 2015 “Renewables 2015 Global Status Report” Renewable Energy Policy Network for the $21^{\text {st }}$ Century ISBN 978-3-9815934-7-1

Ritzer G, Jurgenson N, 2010 “Production, Consumption, Prosumption: The nature of capitalism in the age of the digital 'prosumer"' Journal of Consumer Culture 10 13-36

Ritzer G, Dean P, Jurgenson N, 2012 "The Coming of Age of the Prosumer" American Behavioural Scientist 56 379-398 
Ritzer G, 2014a "Automating prosumption: The decline of the prosumers and the rise of the presuming machines" Cultural Studies 1-18

Ritzer G, 2014b "Prosumption: evolution, revolution, or eternal return of the same?" Journal of Consumer Culture 14(3) 3-24

Sauter R, Watson J, 2007, "Strategies for the deployment of micro-generation: Implications for social acceptance” Energy Policy 35(5) 2770-2779

Schleicher-Tappeser R, 2012 "How renewables will change electricity markets in the next five years?" Energy Policy 48 64-75

Seyfang G, Jin J, Smith A, 2013 "A thousand flowers blooming? An examination of community energy in the UK" Energy Policy 61 977-989

Shove E, 2003 Comfort, Cleanliness and Convenience: The Social Organization of Normality (Oxford, Berg)

Shove E, 2010 "Beyond the ABC: climate change policy and theories of social change" Environment and Planning A 42 1273-1285

Smith A, Kern F, Raven R, Verhees B, 2014 "Spaces for sustainable innovation: Solar photovoltaic electricity in the UK" Technological Forecasting and Social Change 81 115-130

Staffell I, Brett DJL, Brandon N, and Hawkes A, Eds 2015 Domestic Microgeneration: renewable and distributed energy technologies, policies and economics (New York, Routledge)

Strengers Y, 2013 Smart energy technologies in everyday life (Basingstoke, Palgrave Macmillan)

Toffler A, 1980 The Third Wave (New York, Bantam Books)

Van Vliet B, Chappells H, 1999 "The co-provision of utility services: resources, new technologies and consumers" in Shove E, Southerton D, Chappells H, Eds Consumption, Everyday Life and Sustainability, A Reader for the European Science Foundation Summer School 21-26 August

Walker G, 2013 "Inequality, sustainability and capability: locating justice in social practice" In: Shove E and Spurling N, Eds Sustainable Practices: Social theory and climate change (New York, Routledge) 
Walker G, Cass N, 2007 “Carbon reduction, 'the public 'and renewable energy: engaging with socio-technical configurations" Area 39(4) 458-469

Walker G, Karvonen A, Guy S, 2015 “Zero carbon homes and zero carbon living: sociomaterial interdependencies in carbon governance" Transactions of the Institute of British Geographers 40(4) 494-506

Watson J, 2004 “Co-provision in sustainable energy systems: the case of microgeneration" Energy Policy 32(17) 1981-1990

Welch D, 2015 “Systems, actors, ends, narratives and identities” In: Foulds C, Jensen CL, Blue S and Morosanu R, Eds Practices, the Built Environment and Sustainability Responses to the Thinking Note Collection (London, GSI, DIST, BSA CCSG)

Xie C, Bagozzi R, Troye S, 2008 "Trying to Prosume: Toward a theory of consumers as co- creators of value" Journal of the Academy of Marketing Sciences 36 109-122 